\title{
Morphological and Motor-Functional Factors Influencing Fundamental Movement Skills in Eight-Year-Old Children
}

\author{
Frane Zuvela, ${ }^{1}$ Ana Kezic, ${ }^{1,}$ and Sasa Krstulovic ${ }^{1}$ \\ ${ }^{1}$ Faculty of Kinesiology, University Of Split, Split, Croatia \\ "Corresponding author: Ana Kezic, Faculty of Kinesiology, University Of Split, Split, Croatia. Tel: +385-21302440, E-mail: anakezic@kifst.hr \\ Received 2016 March 06; Revised 2016 April 18; Accepted 2016 May 23.
}

\begin{abstract}
Background: Because some children are already being selected for some sports disciplines by the age of eight, it is important to know whether quantitative measurement tests could serve as a good selection tool in this context.

Objectives: The aim of this study was to determine the possible influence of motor-functional abilities and morphological characteristics on fundamental movement skills in eight-year-old children.

Materials and Methods: A total of 90 children ( 45 boys and 45 girls) participated in this study and were subjected to two tests for morphological status assessment (body height and body weight), three tests of motor-functional abilities (forward bow, standing long jump, and 1/4 mile run), and one test of fundamental motor skills (FMS-POLYGON). Multiple regression analysis was used to determine the influence of morphological characteristics and motor-functional abilities on fundamental movement skills.

Results: The results of this study show that explosive strength and endurance are significant predictors of FMS-POLYGON performance in both genders, whereas body height is a significant predictor only in boys.

Conclusions: We conclude that girls with high endurance and strength have better results in the FMS-POLYGON, whereas boys must be taller and have higher degrees of endurance and strength to excel. Future studies should determine the trends and laws of influence concerning the analyzed factors in children of different ages.
\end{abstract}

Keywords: Sex Differences, Motor Skills, Physical Endurance, Flexibility, Muscle Strength

\section{Background}

The assessment of fundamental movement skills (FMS) is an irreplaceable component of a number of professions. There are several ways to measure children's FMS, depending on what information is needed. The quantitative assessment method involves measuring performance outcomes, and precise FMS evaluation is not common in contexts in which a qualitative assessment approach is needed. However, researchers have developed several FMS tests that are based on a quantitative approach $(1,2)$ and can serve as a fairly accurate measure of such skills. FMSPOLYGON (2) is a reliable and valid instrument for FMS assessment in eight-year-old children. The authors discovered a high correlation ( 0.82 ) between the new quantitative test and the test of gross motor development, second edition (TGMD-2) (3), which can be classified as a qualitative FMS test and is commonly used in many studies that investigate the effects of specific treatments on FMS (4-7). This shows that quantitative assessment methods can be as good as qualitative methods in measuring the FMS of children. This is especially important in terms of the applicability of the FMS-POLYGON. The need for a quick and easily administrable test for FMS assessment has been noted in primary schools. FMS-POLYGON has proven to be eas- ily administered and allows for the testing of large groups of children in a short period of time. A number of studies have searched for evidence of a relationship between qualitative FMS tests and motor-functional abilities in children (8-11). Significant associations between FMS and endurance among children aged 13 to 15 years have also been noted (8). The results of a study by Overlock and Jun (10). suggests that balance and motor skill performance are moderately associated with each other in five to nine-year-old children. A strong correlation was also found between FMS and motor abilities in children aged nine to 10 years (11). Another investigation (12) confirmed the significant correlation between striking, catching, throwing, and shooting skills with good results in the static and dynamic balance assessment test. The relationship between FMS as measured by TGMD-2 and motor-functional abilities has also been investigated (2), and researchers state that the correlation exists in the male and female sample populations. All of these studies have measured FMS through qualitative assessment, but no studies using quantitative assessment tools were found.

In addition, in examining the above studies, we note a lack of studies investigating the relationship between motor-functional abilities and FMS in children of early 
school age. Because children are already being selected for some sports by their eighth year of life, it is important to determine whether FMS-POLYGON could serve as a good selection tool. Research also suggests that early sampling can lead to numerous positive growth and developmental opportunities. Several researchers have also demonstrated that the early sampling pathway is beneficial to long-term talent development in sports (13).

\section{Objectives}

The main aim of this study was to determine the influence of some motor-functional abilities and morphological characteristics on the FMS of eight-year-old boys and girls.

\section{Materials and Methods}

\subsection{Participants}

Ninety second graders ( 45 boys and 45 girls) aged eight $(8.1 \pm 0.4)$ years and attending elementary schools in Split, Croatia participated in the investigation, which was carried out during May of 2014. On average, the boys were involved in organized physical activity for $118.63 \pm 114.11 \mathrm{~min}$ utes per week, whereas the girls had slightly higher results of $125.21 \pm 106.79$ minutes per week. Weekly sedentary activity was significantly higher (boys: $1284.06 \pm 375.81 \mathrm{~min}-$ utes per week, girls: $1387.97 \pm 379.20$ minutes per week).

All of the children were chosen randomly. The children gave verbal consent, and their parents gave written informed consent. This study only included children with no health problems or significant motor disorders. The study protocol conforms to the ethical guidelines of the 1975 declaration of Helsinki as reflected in a priori approval by the institution's (university of Split, faculty of kinesiology) human research committee.

\subsection{Measurements}

\subsubsection{Motor-Functional Abilities}

Three variables were used to assess the motorfunctional status of the children. The variables were selected according to the results of previous studies (14). The test for flexibility was a simple sit-and-reach test (SITREACH, $1 \mathrm{~cm}$ ), explosive strength was measured using a long jump from a standing position (ST-L-JUMP, $1 \mathrm{~cm}$ ), and cardiovascular endurance was evaluated by measuring the time that was needed to cover $1 / 4$ of a mile (1/4-MILE, 0.1 s). The first two tests were performed three times, with an appropriate rest in between. The mean of the three scores was used in a later analysis.

\subsubsection{Fundamental Movement Skills}

The FMS test (FMS-POLYGON) (2) was used to assess the children's FMS (Figure 1). According to previous studies (15, $16)$, this test is valid and reliable in school children. The FMS-POLYGON consists of four tests: consecutively tossing and catching a volleyball against a wall (Figure 1A), running across obstacles (Figure 1B), carrying medicine balls (Figure $1 C$ ), and straight running (Figure 1D). An area of $10 \times 24$ meters with 14 cones, three obstacles, two medicine balls, a volleyball, a Swedish vault, and four pairs of photocells are needed for the FMS-POLYGON. The participants stand on a starting line with the volleyball and begin the first task of tossing and catching the ball against a wall six times on the examiner's signal. They then leave the ball and run across three obstacles, finally passing through the cones. Participants then lift and carry the first and the second medicine ball and put them on the Swedish vault, then run 20 meters until passing through the photocells. It is important to emphasize that the middle obstacle must be moved aside before the run. The result of the test is the time (in seconds) needed to successfully accomplish the above four tasks.

\subsection{Data Analysis}

Data were analyzed using the Statistica for windows 7.0 package, and the statistical significance was set at $\mathrm{P} \leq 0.05$. Basic descriptive statistics were calculated: mean value, standard deviation, and minimum and maximum results. Multiple regression analysis was used to determine the influence of the set of anthropometric and motor variables on FMS.

\section{Results}

The basic statistics for eight-year-old boys and girls are shown in Table 1. Boys averaged $134.0 \mathrm{~cm}$ in height and $30.3 \mathrm{~kg}$ in weight. Girls averaged $134.1 \mathrm{~cm}$ in height and $30.1 \mathrm{~kg}$ in weight. When gender differences are observed, it is obvious that the girls were significantly more flexible, whereas the boys scored higher in strength and endurance, although without significant differences. In addition, boys needed less time to complete the FMS-POLYGON tasks. According to the Kolmogorov-Smirnov test, all variables were normally distributed.

Multiple regression analyses (Table 2) were used to determine the statistically significant influence of a set of morphological and motor variables on the FMS-POLYGON results in both boys and girls. In boys, the multiple correlation coefficient has a value of 0.81 ( $\mathrm{P}<0.001$ ), and $69 \%$ of the common variance can be explained with the chosen predictive set of variables, which means that only $31 \%$ of the total variability of the criterion can be ascribed to other 


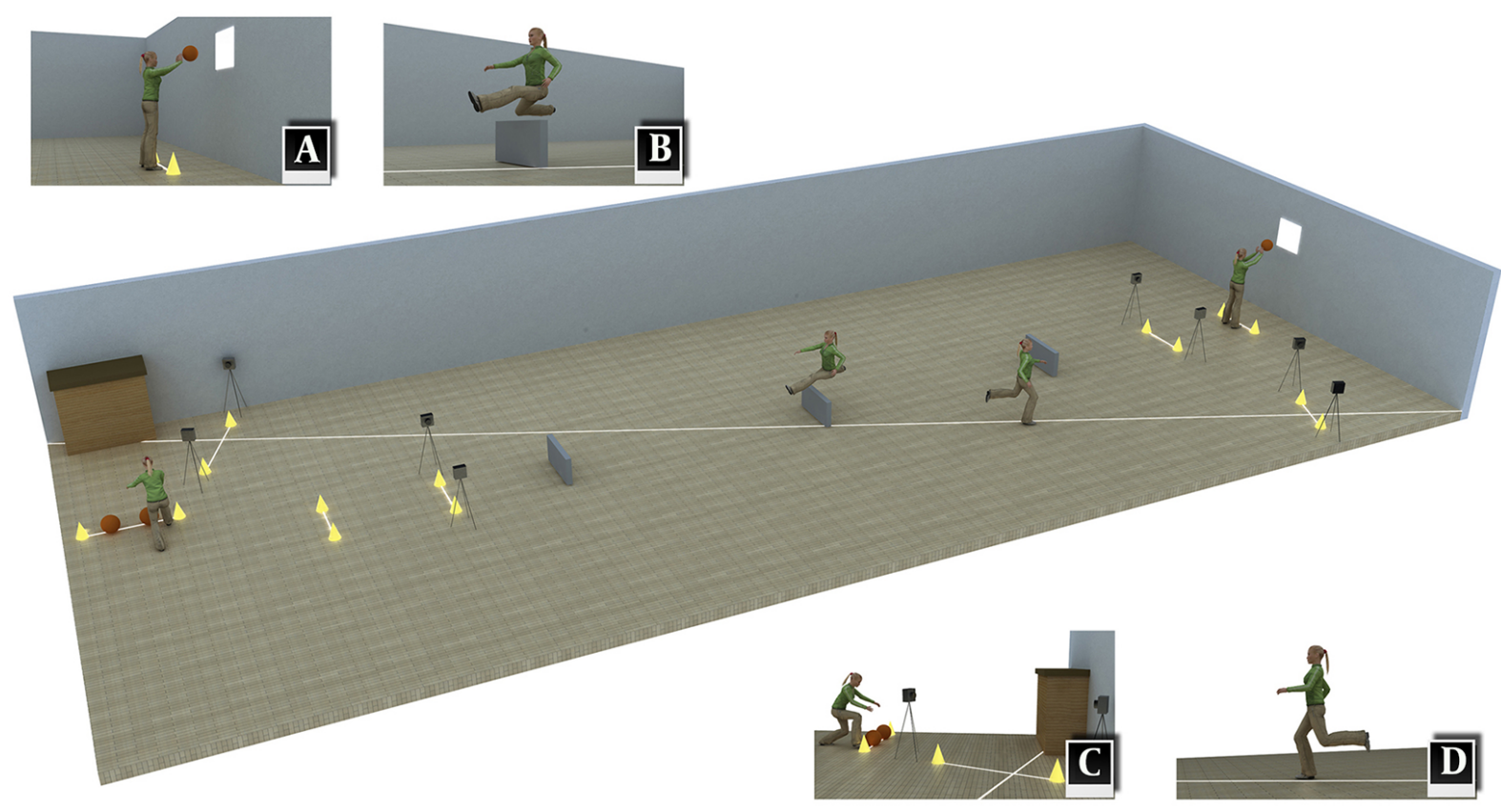

Figure 1. Fundamental Movement Skills Test

Table 1. Basic Statistics of All Variables for Boys and Girls; the Results of the T-Test Between the Genders ${ }^{\mathrm{a}}$

\begin{tabular}{|c|c|c|c|c|c|c|c|}
\hline \multirow[t]{2}{*}{ Variables } & \multicolumn{3}{|c|}{ Boys, $n=45$} & \multicolumn{3}{|c|}{ Girls, $n=45$} & \multirow[t]{2}{*}{ T-Test (P Value) } \\
\hline & Mean \pm SD & MIN & MAX & Mean \pm SD & MIN & MAX & \\
\hline Body height, cm & $134.0 \pm 5.5$ & 121.3 & 146.6 & $134.1 \pm 5.1$ & 123.1 & 147.2 & 0.94 \\
\hline Body weight, kg & $30.3 \pm 5.9$ & 21.0 & 49.1 & $30.1 \pm 5.7$ & 19.0 & 48.0 & 0.94 \\
\hline SIT-REACH, cm & $27.7 \pm 7.1$ & 12.0 & 43.0 & $36.9 \pm 9.2$ & 11.0 & 58.0 & 0.00 \\
\hline ST-L-JUMP, cm & $131.8 \pm 18.3$ & 89.3 & 176.7 & $126.7 \pm 13.6$ & 91.0 & 159.3 & 0.08 \\
\hline 1/4-MILE, $s$ & $138.4 \pm 18.6$ & 101.2 & 173.6 & $145.2 \pm 21.6$ & 108.6 & 196.5 & 0.10 \\
\hline FMS-POLYGON, s & $23.93 \pm 2.82$ & 19.96 & 31.47 & $24.46 \pm 1.94$ & 20.20 & 28.95 & 0.30 \\
\hline
\end{tabular}

${ }^{a}$ MAX, maximum result; Mean, mean value; MIN, minimum result; SD, standard deviation; SIT-REACH, sit and reach test; ST-L-JUMP, standing long jump test; $1 / 4-M I L E, 1 / 4$ mile test.

anthropologic characteristics. For girls, the multiple correlation coefficient was $0.65(\mathrm{P}<0.001)$, and the predictive set of variables explains $42 \%$ of the total variability of the criterion.

Based on the analysis of each predictor, the statistically significant influence on the criterion is recorded for the explosive strength test (boys: $\mathrm{B}=-.50, \mathrm{P}<0.001$; girls: $\mathrm{B}=-.39$, $\mathrm{P}<0.001$ ) and the endurance test (boys: $\mathrm{B}=.43, \mathrm{P}<0.001$; girls: $\mathrm{B}=.49, \mathrm{P}<0.001)$ for both genders. In addition, body height had a statistically significant influence on the criterion, but only in boys $(\mathrm{B}=-0.32, \mathrm{P}<0.021)$.

\section{Discussion}

The main aim of this study was to determine the influence of some motor-functional abilities and morphological characteristics on the FMS of eight-year-old boys and girls. On average, boys perform better in tests for endurance, explosive strength, and fundamental motor skills, whereas girls are better than boys in flexibility. Generally, girls with high endurance and explosive strength accomplish better results in FMS. To achieve greater results in FMS-POLYGON, boys must have greater body height in addition to possessing high endurance and explosive strength.

Gender differences in motor abilities favor boys during prepubertal ages. Factors influencing gender differ- 
Table 2. Regression Analysis of Morphological Characteristics, Motor-Functional Abilities, and Success in FMS-POLYGON ${ }^{\mathrm{a}}$

\begin{tabular}{|c|c|c|c|c|}
\hline \multirow[t]{3}{*}{ Variables } & \multicolumn{4}{|c|}{ FMS-POLYGON } \\
\hline & \multicolumn{2}{|c|}{ Boys, $n=45$} & \multicolumn{2}{|c|}{ Girls, $n=45$} \\
\hline & BETA & P-level & BETA & P-level \\
\hline Body height, cm & -0.32 & 0.02 & -0.22 & 0.19 \\
\hline Body weight, kg & 0.07 & 0.61 & -0.02 & 0.91 \\
\hline SIT-REACH, cm & 0.03 & 0.74 & 0.04 & 0.77 \\
\hline ST-L-JUMP, cm & -0.50 & 0.00 & -0.39 & 0.00 \\
\hline 1/4-MILE, $s$ & 0.43 & 0.00 & 0.49 & 0.00 \\
\hline $\mathbf{R Q}$ & \multicolumn{2}{|c|}{0.81} & \multicolumn{2}{|c|}{0.65} \\
\hline RQ2 & \multicolumn{2}{|c|}{$69 \%$} & \multicolumn{2}{|c|}{$42 \%$} \\
\hline P-level & \multicolumn{2}{|c|}{0.00} & \multicolumn{2}{|c|}{0.00} \\
\hline
\end{tabular}

ences may be attributed to the differing degrees of encouragement, practice opportunities, and reinforcement patterns of boys and girls inside and outside the school setting (17). This research confirms earlier findings about boys' preference for manipulative activities and girls' for locomotion activities. An overview of the results concerning sexual dimorphism in motor abilities has been presented (18). As a rule, boys score higher in motor tests of strength and endurance (19), which was also the case in the current study. However, girls had better results in the flexibility test, which confirms certain studies (20).

Some studies (21-23) have found certain body compositions to be negatively related to locomotor skill proficiency. Body mass index (BMI) was used as a measure for body composition, and lower motor skill level was found in obese children than in normal-weight peers (24). Because use of BMI may lead to imprecise evaluations, it is not always suitable for body composition assessment (25), and it is not clear whether children in the mentioned study had lower motor skill levels because they had lower body height or higher body weight. For this reason, BMI was not used in the current study.

Starting from the premise that success in almost all kinesiological activities is determined by a combination of various related factors and using multiple regression analysis, we determined the impact of morphological and motor variables on FMS. Given the differences between the genders in motor abilities, we investigated the effect of these variables on FMS according to gender. A significant influence of endurance (1.4 mile run) on FMS is in accordance with other studies (8), which state that performance in tasks involving locomotor (running and jumping) and object control skills (catching, throwing, hitting, and shooting) is significantly correlated with the results of the multistage fitness test. The authors have suggested further research in order to more precisely identify the rela- tionship between endurance and FMS, which was done in the current study.

A significant relationship between explosive strength (standing long jump) and fundamental movement skills is expected. The standing long jump test is an integral part of the TGMD-2, which is used to assess the quality of gross motor skills. Specifically, based on the definition of quantitative approach, the standing long jump is a test of explosive strength. However, the same test is recognized as a test for assessing gross motor skills, and it focuses on estimating the quality of performance. This suggests the need for further research to more clearly define whether the applied test is used for assessing motor skills and/or motor abilities of children. Confirmation of the obtained results was found in recent studies analyzing the relationship between qualitative and quantitative FMS assessments (2). The authors found a significant correlation between average throwing distance and the quality of performance in the overhand throw in children aged seven to 12 . Other studies (26) have also reported a significant correlation between qualitative and quantitative assessments in primary school children.

According to these findings, it can be concluded that certain connections between motor-functional abilities and FMS can be quantified and can explain a great percentage of common variance. In addition, these abilities appear to develop in parallel under the influence of genetics, nutrition, and various physical activities. However, the results point to certain gender differences, which are primarily manifested through morphological structure. For example, body height proved to have a positive influence on FMS-POLYGON success only in boys. By reviewing the tasks in FMS-POLYGON, it can be assumed that taller boys had the advantage in the tossing and catching the volleyball against a wall task, which had to be done over a mark that was $150 \mathrm{~cm}$ high. It was also probably easier for taller boys 
to clear the $50 \mathrm{~cm}$ high obstacle and run, because running speed is directly related to two factors: frequency of movement and stride length. It is clear that factors other than motor-functional ability and morphological characteristics also influence the rate of adoption and implementation of quality movement skills in children of early school age; these factors include social and economic status and nutrition habits. We have not evaluated these dimensions, and future research into this issue should take them into account.

\subsection{Conclusion}

According to the results presented and discussed, the following conclusions can be drawn:

1. Predictors of success on the FMS-POLYGON are very similar for boys and girls.

2. Success in explosive strength and endurance tests has a significant impact on success in the FMS-POLYGON in both genders.

3. The greatest predictive value doe FMS-POLYGON results is the explosive strength test results, probably due to the nature of the FMS-POLYGON.

4. Boys with greater body height had the advantage in some FMS-POLYGON tasks.

5. Because contemporary sport requirements generally favor taller, faster athletes with higher degrees of endurance, it can be assumed that FMS-POLYGON can serve as a tool to identify talented athletes.

\section{References}

1. Education Department of Western Australi . Fundamental Movement Skills Teacher Resource. Perth. Australi: Education Department of Western Australi; 2001.

2. Zuvela F, Bozanic A, Miletic D. POLYGON - A New Fundamental Movement Skills Test for 8 Year Old Children: Construction and Validation. J Sports Sci Med. 2011;10(1):157-63. [PubMed: 24149309].

3. Ulrich DA. Test of Gross Motor Development. 2 ed. Austin: Pro-ed; 2000.

4. Akbari H,Abdoli B, Shafizadeh M, Khalaji H, Hajihosseini S, Ziaee V. The effect of traditional games in fundamental motor skill development in 7-9 year-old boys. Iran J Pediatr. 2010;19(2):123-9.

5. Bakhtiari S, Shafinia P, Ziaee V. Effects of selected exercises on elementary school third grade girl students' motor development. Asian J Sports Med. 2011;2(1):51-6. [PubMed: 22375218].

6. Kordi R, Nourian R, Ghayour M, Kordi M, Younesian A. Development and evaluation of a basic physical and sports activity program for preschool children in nursery schools in iran: an interventional study. Iran J Pediatr. 2012;22(3):357-63. [PubMed: 23400235].

7. Mostafavi R, Ziaee V, Akbari H, Haji-Hosseini S. The Effects of SPARK Physical Education Program on Fundamental Motor Skills in 4-6 YearOld Children. Iran J Pediatr. 2013;23(2):216-9. [PubMed: 23724186].
8. Okely AD, Booth ML, Patterson JW. Relationship of physical activity to fundamental movement skills among adolescents. Med Sci Sports Exerc. 2001;33(11):1899-904. [PubMed: 11689741].

9. Gallahue DL, Donnelly FC. Developmental Physical Education for All Children. 4 ed. Champaign: IL: Human Kinetics; 2003.

10. Overlock JA, Yun J. The relationship between balance and fundamental motor skills in children.J Hum Mov Stud. 2006;50(1):29-46.

11. Haga M. The relationship between physical fitness and motor competence in children. Child Care Health Dev. 2008;34(3):329-34. doi: 10.1111/j.1365-2214.2008.00814.x. [PubMed: 18410639].

12. Butterfield SA, Loovis EM. Kicking, catching, throwing and striking development by children in grades K-8: Preliminary findings. J Hum Mov Stud. 1998;34(2):67-81.

13. Fransen J, Pion J, Vandendriessche J, Vandorpe B, Vaeyens R, Lenoir $\mathrm{M}$, et al. Differences in physical fitness and gross motor coordination in boys aged 6-12 years specializing in one versus sampling more than one sport. J Sports Sci. 2012;30(4):379-86. doi: 10.1080/02640414.2011.642808. [PubMed: 22214429].

14. Krstulović S, Maleš B, Žuvela F, Erceg M, Miletić. Judo, soccer and trackand-field differential effects on some anthropological characteristics in seven-year-old boys. Kinesiol. 2010;42(1):56-64.

15. Culjak Z, Miletic D, Kalinski SD, Kezic A, Zuvela F. Fundamental movement skills development under the influence of a gymnastics program and everyday physical activity in seven-year-old children. Iran jped. 2014;24(2):124.

16. Franjko I, Žuvela F, Kuna D, Kezić A. Relations between Some Anthropometric Characteristics and Fundamental Movement Skills in EightYear-Old Children. Croat J Edu. 2013;15(4):195-209.

17. Jürimäe T, Jürimäe J. Growth, Physical Activity and Motor Development in Prepubertal Children. Growth, Physical Activity and Motor Development in Prepubertal Children: CRC Press; 2000.

18. Malina RM, Bouchard C. Growth, Maturation and Physical Activity. Champaign: Human Kinetics; 1991.

19. Milne C, Seefeldt V, Reuschlein P. Relationship between grade, sex, race, and motor performance in young children. Res Q. 1976;47(4):726-30. [PubMed:1070745].

20. Branta C, Haubenstricker J, Seefeldt V. Age changes in motor skills during childhood and adolescence. Exerc Sport Sci Rev. 1984;12:467520. [PubMed: 6734680].

21. Marshall JD, Bouffard M. The effects of quality daily physical education on movement competency in obese versus nonobese children. APAQ. 1997;14(3):222-37.

22. Okely AD, Booth ML, Chey T. Relationships between body composition and fundamental movement skills among children and adolescents. Res Q Exerc Sport. 2004;75(3):238-47. doi: 10.1080/02701367.2004.10609157. [PubMed: 15487288].

23. Southall JE, Okely AD, Steele JR. Actual and perceived physical competence in overweight and nonoverweight children. Pediatr Exerc Sci. 2004;16(1):15-24.

24. E DH, Deforche B, De Bourdeaudhuij I, Lenoir M. Relationship between motor skill and body mass index in 5- to 10-year-old children. Adapt Phys Activ Q. 2009;26(1):21-37. [PubMed:19246771].

25. Glaner MF. Body Mass Index As Signalize The Body Fat To Comparing As To The Skinfold. Med Sci Sport Exer. 2005;37:S300-1. doi: 10.1097/00005768-200505001-01571.

26. Roberton MA, Konczak J. Predicting children's overarm throw ball velocities from their developmental levels in throwing. Res $Q$ Exerc Sport. 2001;72(2):91-103. doi: 10.1080/02701367.2001.10608939. [PubMed: 11393884]. 